\title{
O MAGISTÉRIO DE ENSINO SECUNDÁRIO E A REGULAMENTAC̣ÃO DA PROFISSÃO (1931-1946)
}

Amália Dias*

RESUMO: Apresentamos as políticas públicas destinadas a regular o estatuto econômico do magistério particular de Ensino Secundário, em face do contexto histórico de organização das relações trabalhistas e da expansão do setor privado no ensino no pós-1930. A partir da atuação do associativismo docente, examinamos as correlações de força entre órgãos do governo, empregadores e magistério particular na definição de contratos de trabalho e registro profissional, posto que a legislação é produto de relações sociais e de poder. Sob a égide do governo federal, essas relações foram canalizadas para o interior das agências estatais, o que, contudo, não anulou as dimensões de conflito intraestatais e entre sujeitos coletivos organizados que encaminharam suas propostas, manifestaram resistências, articularam alianças e disputaram a hegemonia do processo decisório.

Palavras-chave: Estado. Magistério. Ensino Secundário.

\section{SECONDARY SCHOOL TEACHING AND ITS PROFESSIONAL REGULATION (1931-1946)}

ABSTRACT: The public policies intended to regulate the economic state of private teaching in secondary education are presented, with the historical context of its (secondary education's) organization, in mind, including its working relations and the expansion of the private sector in teaching post-1930. From the teaching association's performance, we are able to examine the correlative forces between the government agencies, employers and the teaching profession, in the definition of work contracts and professional register, since it follows that legislation is a product of social relations and power. Under the aegis of the federal government, these relations have become part of the remit of state agencies, but this, in actual fact, hasn't eradicated the dimension of interstate conflict and, between the organized collective subjects that have forwarded their proposals, resistance has become apparent, alliances have been articulated and the hegemony of the decision-making process has been disputed by them.

Keywords: State. Teaching. Secondary Education.

* Mestre em Educação pela Universidade Federal Fluminense (UFF) e Doutoranda em Educação, linha História Social da Educação, pela na Universidade Federal Fluminense (UFF). E-mail: amaliadias@gmail.com 


\section{Introdução}

As iniciativas do Estado, no pós-1930, para organizar a formação, a seleção, o campo de trabalho e o estatuto profissional dos professores do Ensino Secundário público e particular remetem à reforma educacional de Francisco Campos, em 1931, e aos seus decretos de regulamentação (VICENTINI; LUGLI, 2005).

É pertinente assinalar que a ação do governo federal sobre a regulamentação do magistério de Ensino Secundário, durante as décadas de 1930 e 1940, pretendia estabelecer modelos de formação, critérios de ingresso e condições para permanência na profissão que deveriam vigorar em todo o país. Porém, foi distinta a mediação das agências estatais e a dos sujeitos coletivos organizados na regulamentação das políticas de profissionalização do magistério particular e do magistério público (DIAS, 2008). Neste artigo, focaliza-se a análise da correlação de forças entre agências do Estado, empregadores e docentes na regulamentação federal dos contratos de trabalho do magistério particular.

Na República, até a Reforma Francisco Campos (BRASIL, 1931; 1932), os professores da rede particular de ensino secundário eram "profissionais liberais", lecionavam em salas alugadas, regulavam os custos e o funcionamento do serviço que prestavam, posto que não havia regulamentação oficial sobre o exercício do magistério. Porém, não viviam apenas das aulas particulares. Lecionavam em cursos e colégios, nos quais recebiam por aula ministrada, sem pagamento em feriados e período de férias escolares. Eram autônomos e empregados, constituindo uma categoria profissional "semi-assalariada" (COELHO, 1988, p. 11).

A Reforma Francisco Campos (BRASIL, 1931) tornou obrigatória a frequência regular ao Ensino Secundário e representou o aval do Estado para a expansão da rede privada no ensino, o que reeordenou os postos de trabalho para o interior das instituições. Por meio da criação da inspeção federal nos estabelecimentos, com o objetivo de validar os diplomas expedidos por aquelas instituições, o Estado empreendeu uma política de equiparações do ensino privado ao ensino público (ROCHA, 2000).

Assim, os donos de estabelecimentos de ensino secundário poderiam assegurar à sua clientela um retorno legal aos investimentos aplicados no setor. A política de equiparações entre público e privado cor- 
respondeu, também, ao início do período de "empresariamento do ensino privado", com o surgimento de interesses empresariais no setor do Ensino Médio, principalmente no curso secundário (ROCHA, 2000, p. 141).

Foi em conformidade com essa política de equiparações dos estabelecimentos de ensino privado que o dispositivo de consolidação da reforma do Ensino Secundário criou, para as escolas, a obrigatoriedade de formalizar, por escrito, contratos de trabalho com os professores (BRASIL, 1932).

Segundo Ricardo Coelho (1988), na capital federal, os donos de estabelecimentos de ensino preferiram manter-se na órbita do Ministério da Educação e Saúde Pública (MESP), firmando contratos restritos ao período letivo com os professores, no lugar de assinar a carteira profissional e subordinar-se à fiscalização do Ministério do Trabalho, Indústria e Comércio (MTIC). Mas, o Sindicato dos Professores do Distrito Federal, criado em 1931, mobilizou-se pelo cumprimento, por parte dos empregadores, do decreto que instituiu a carteira profissional, em 1932, exatamente porque aquele documento tinha validade perante o MTIC.

Foi ampla a atividade do Sindicato de Professores do Distrito Federal em prol do registro dos contratos de trabalho na carteira profissional, posto que a regulamentação dos contratos implicava definições sobre a jornada de trabalho, as férias e a fixação de critérios para remuneração dos professores.

Diante do impasse nas negociações com os empregadores sobre os contratos de trabalho, o Sindicato dos Professores do Distrito Federal recorreu ao MTIC, no qual obteve, em abril de 1932, anteprojeto de lei referente à locação de trabalho do magistério particular, que asseguraria aos professores direitos trabalhistas e de previdência social, o que significava enorme avanço para uma categoria profissional que ainda não possuía amparo legal (COELHO, 1988).

Em defesa da melhoria do ensino e das condições de trabalho, o Sindicato de Professores do Distrito Federal mobilizou campanha a favor da aprovação do anteprojeto proveniente do MTIC, organizando manifestações que tiveram ampla cobertura jornalística e o apoio da opinião pública, sendo seus representantes recebidos pelo presidente Getúlio Vargas. Os representantes do magistério particular argumentavam que, sob o amparo da legislação trabalhista, os docentes não precisariam se 
submeter às pressões dos empregadores, que condicionavam sua permanência no emprego aos índices de aprovação de alunos. Argumentavam também que a estabilidade nos empregos possibilitaria o investimento no aperfeiçoamento profissional (COELHO, 1988, p. 99).

A princípio, os empregadores e seus principais expoentes combateram a aprovação do anteprojeto, criticando a gestão do Estado nas relações entre capital e trabalho e alegando os prejuízos aos alunos, em razão da majoração do custo do ensino para o pagamento de férias aos professores, entre outros argumentos contrários à regulamentação dos contratos.

Em um segundo momento, os empregadores decidiram negociar a regulamentação dos contratos de trabalho, explicitando essa reorientação em função das garantias que os contratos também representariam para os empregadores perante a legislação trabalhista. Isso porque os empregadores vinham sendo acionados pelas Juntas de Conciliação, em face de demissões e da redução de salários de professores. Defendiam que a forma de regulação dos contratos fosse definida no âmbito do Ministério da Educação, a fim de manterem autonomia junto ao MTIC.

Provavelmente, foi a influente resistência dos empregadores que concorreu para que o anteprojeto sobre os contratos de trabalho ficasse detido para estudo no MESP, chegando a desaparecer por duas vezes e só obtendo parecer favorável em fevereiro de 1933, após a saída de Francisco Campos da pasta (substituído por Washington Pires, em setembro de 1932). Ainda em 1933, os empregadores, organizados no "Sindicato de Proprietários e Diretores de Institutos de Ensino Secundário e Comercial do Rio de Janeiro", designaram uma comissão, dirigida pelo professor LaFayette Côrtes, para negociar com os ministros da Educação e do Trabalho a respeito dos contratos de trabalho (COELHO, 1988, p. 98).

Esse cenário se transformou com a implantação do Estado Novo, posto que, com o fechamento dos órgãos legislativos, ficou a cargo apenas do MTIC a regulamentação dos contratos de trabalho dos professores. Isso contrariou a intenção dos empregadores de manter a questão no âmbito do Ministério da Educação, onde tinham mais influência (COELHO, 1988, p. 114).

Em 1939, o Ministério do Trabalho designou comissão para elaboração de anteprojeto de lei sobre os contratos de trabalho do magistério particular, com a participação de representantes do Ministério da 
Educação e Saúde. A comissão era composta por Luiz do Rego Monteiro e Max Monteiro, da parte do MTIC, Antonio Figueira de Almeida, técnico do Ministério da Educação e Saúde (MES) ${ }^{1}$, Abgar Renault, diretor do Departamento Nacional de Educação, e Lourenço Filho, diretor do Instituto Nacional de Estudos Pedagógicos (Inep).

Documentos existentes no arquivo de Gustavo Capanema, depositados no Centro de Pesquisa e Documentação de História Contemporânea do Brasil, da Fundação Getúlio Vargas (FGV/CPDOC), permitem conhecer a tramitação do processo, a disputa entre representantes do MES e do MTIC, no que diz respeito a que órgão caberia a competência no assunto, as divergências, os impasses e as negociações.

Existem também memoriais encaminhados pelo Sindicato dos Professores ao Ministro da Educação e Saúde, Gustavo Capanema, solicitando e sugerindo resoluções sobre o assunto. São fontes documentais que permitem apreender a correlação de forças, os sujeitos e as estratégias que atuavam sobre a gestação de políticas públicas que incidiam sobre o campo de atuação profissional do magistério do Ensino Secundário.

Logo, ao identificar e examinar a atuação do Estado em medidas que repercutiam ou incidiam diretamente sobre o magistério de Ensino Secundário, não estamos entendendo o Estado como um ente homogêneo que paira sobre a sociedade apática e dita os parâmetros da profissionalização via legislação. A partir do referencial teórico de Antonio Gramsci (2007) é que se compreende o Estado como uma relação social entre muitos sujeitos, coletivamente organizados, que, nas casamatas da burocracia estatal, mas também por meio de instituições e agências da sociedade civil, fazem representar seus interesses e concepções de mundo na condução de questões que lhes são afetas e que dizem respeito à direção da sociedade. É na correlação de forças entre esses grupos e agências que se configura o Estado.

\section{0 debate da qualificação do professor na elaboração do decreto de regulamentação}

Com a finalidade de contribuir, como integrante da comissão organizada em 1939, Lourenço Filho (1939) elaborou um documento no qual apresentou os termos da qualificação do magistério. Esclarecia que a tarefa da comissão 
[...] subentende a definição da profissão e, necessariamente, a "qualificação" do profissional. É em virtude de alto interesse social que o Estado estabelece a regulamentação das profissões. Esse interesse não atende apenas a imperativos gerais de organização do trabalho, mas também a proteção dos profissionais "qualificados" contra os não "qualificados". No caso do exercício do magistério, em todos os graus e ramos, os interesses de ordem pública sobrelevam aos de origem particular. Na formação e orientação da infância e da juventude se empenha o próprio Estado.

Lourenço Filho justificava a competência do Estado na definição de normas para o exercício do magistério público e particular, "e das condições de qualificação dos que pretendem exercê-lo", fundamentado nos termos da legislação vigente sobre a responsabilidade do Estado no estabelecimento das diretrizes educacionais e na proteção ao direito de trabalho. Defendia que a lei deveria exigir mais do que o "exercício do ensino" como critério de distinção de "um gênero de trabalho adotado como profissão” (LOURENÇO FILHO, 1939).

Sob essa ótica, Lourenço Filho ponderava que os critérios para a definição da profissão de magistério dependiam "da fixação dos objetivos do próprio ensino, condições de idade dos alunos, de tipos de organização de estabelecimentos, dos periodos de trabalho, além de outras" (LOURENÇO FILHO, 1939, grifos do autor). Por sua vez, a organização das funções do ensino e seu funcionamento "dependem de aspectos de cultura geral, de aspectos de preparação ou de cultura estritamente técnico-pedagógica, e dos aspectos gerais ou particulares de ordem pública que o exercício do magistério, como profissão, possa envolver" (LOURENÇO FILHO, 1939).

$\mathrm{Na}$ forma como o assunto é demarcado por Lourenço Filho, dispor sobre a regulamentação da profissão docente, estabelecendo normas para a contratação de professores, demandava discutir a habilitação do professorado. $\mathrm{O}$ estatuto profissional e econômico era atrelado à habilitação, à qualificação, à formação e ao preparo do professor para exercício do ofício.

Nesse estudo, Lourenço Filho considerava a matéria da qualificação do professor não apenas em função do magistério do Ensino Secundário, mas apontava a necessidade de regulamentação da habilitação - conforme modalidade e objetivos de ensino - do magistério de Ensino Primário, Profissional, Normal, todos sem regulamentação até 1939. Asseverava que, até aquele momento, havia regulamentação "de modo 
mais ou menos conveniente" da qualificação dos professores de institutos de Ensino Superior e de estabelecimentos de Ensino Secundário, oficializados ou equiparados, e de professores do Ensino Comercial.

A respeito da qualificação do professor do Ensino Secundário, Lourenço Filho (1939) retomava como parâmetros a inscrição no Registro de Professores e a formação do docente na Faculdade de Educação, Ciências e Letras, ou habilitação perante a faculdade, para aqueles em exercício. O Registro por disciplina lecionada foi criado, em 1931, no Departamento Nacional de Ensino e pretendia conceder autorização para os candidatos ao exercício do magistério do Ensino Secundário. Após a instalação da Faculdade de Educação, Ciências e Letras e enquanto não houvesse diplomados, os professores deveriam apresentar certificados de aprovação, obtidos nessa instituição, em exames das matérias para as quais a inscrição fosse requerida e, ainda, de Pedagogia Geral e de Metodologia das mesmas disciplinas. Por isto, até o funcionamento da faculdade, os professores obteriam somente um registro provisório (DIAS, 2008).

Porém, como a faculdade não havia sido instalada e o registro provisório foi concedido e mantido por sucessivas autorizações, Lourenço Filho avaliava que ainda não eram satisfatórios e eficientes os meios de qualificação do magistério de Ensino Secundário.

Ao focalizar especificamente a situação do magistério particular, Lourenço Filho sustentava a qualificação como requisito a ser considerado na regulamentação da profissão e a necessidade de legislação geral "no sentido de nacional", e insistia na competência dos órgãos do Ministério da Educação em definir o assunto (LOURENÇO FILHO,1939).

Sob essa perspectiva, Lourenço Filho propôs a criação de um registro geral dos professores qualificados, de todos os graus e ramos do ensino, regulado pelo Ministério da Educação e Saúde e verificador da capacidade física, intelectual, moral e técnica do professor. Após essa comprovação é que deveria ser concedida a carteira profissional que possibilitaria o acesso à Justiça do Trabalho (LOURENÇO FILHO, 1939).

Ao informar ao ministro Capanema suas impressões sobre o anteprojeto de lei elaborado pela comissão interministerial, Lourenço Filho (1940) contou que, no início dos trabalhos da Comissão, houve acordo sobre a importância da qualificação do magistério particular, mas que essa questão seria regulada em uma ou mais leis, segundo os estudos em andamento no MES, no âmbito do Departamento Nacional de 
Educação e do Conselho Nacional de Educação (CNE). Observou que os representantes do Ministério da Educação na comissão discordavam do teor do anteprojeto, porque este pretendia apenas regular os contratos de trabalho do magistério do Ensino Secundário particular fiscalizado, quando a competência da comissão indicava a regulamentação do magistério particular em qualquer situação de trabalho. $\mathrm{O}$ anteprojeto abrangia também o exercício do trabalho inclusive dos diretores dos estabelecimentos, dos funcionários de secretaria e de serviços gerais. $\mathrm{Na}$ análise de Lourenço Filho, ao contrário do que foi acordado, ao dispor sobre a qualificação do professor particular, o anteprojeto não considerou os estudos em andamento do Ministério da Educação e Saúde. Por esses motivos, os representantes do MES na comissão solicitaram providências ao ministro da Educação, a fim de evitar "que problema de tal gravidade não venha a ter solução inadequada, com a transformação em lei do anteprojeto" (LOURENÇO FILHO, 1939).

O ministro do Trabalho Valdemar Falcão (1939), ao enviar ao presidente Getúlio Vargas o anteprojeto de lei resultante dos trabalhos da comissão, também informou ao presidente que não havia sido possível à comissão chegar a "conclusões unânimes" porque seus membros divergiram, especialmente no tocante à "qualificação profissional", e que Lourenço Filho entendia que não deveria haver, no projeto, dispositivo sobre a qualificação profissional, em oposição à opinião da maioria da comissão.

Em função dessa discordância é que o ministro do Trabalho submeteu ao presidente "medidas referentes exclusivamente ao regime de trabalho e à condição dos professores como empregados, a fim de amparálos nessa qualidade, evitando, entretanto, o que pudesse ser objeto de controvérsias ou dissesse respeito ao campo da educação", isto é, a questão da remuneração dos professores (FALCÃO, 1939).

Dessa forma, o projeto abrangia questões sobre a duração do trabalho do professor, a forma e a garantia de remuneração, e a instituição do registro profissional mediante comprovação de habilitação, expedida pelas autoridades em matéria de educação. Para Valdemar Falcão, embora o anteprojeto não contemplasse todas as questões do exercício do professorado, assegurava aos professores "justas condições de trabalho e uma efetiva proteção, atendido por essa forma o dever do Estado, de amparar aqueles que se dedicam a uma das mais distintas atividades sociais" (FALCÃO, 1939). 
O ministro da Educação e Saúde, Gustavo Capanema (1940), sugeriu algumas emendas ao anteprojeto de decreto-lei, mas que não chegaram a modificar a substância do texto, como o próprio ministro reconhecia.

Após meses de trabalho, e em face das negociações e divergências mencionadas, em 1940, era sancionado o primeiro decreto-lei a dispor sobre o trabalho no magistério particular. Por essa regulamentação, os professores e auxiliares da administração escolar foram equiparados aos comerciários, sendo estendidos a eles "todos os preceitos da legislação de proteção e assistência aos trabalhadores e de previdência social" (BRASIL, 1940a). Em 1943, o conteúdo desse decreto repetia-se na Consolidação das Leis Trabalhistas (BRASIL, 1943).

A Consolidação das Leis Trabalhistas, organizada durante o Estado Novo, significou a reunião, num mesmo código, das normas tutelares do trabalho. Pretendeu ser a sistematização da legislação produzida desde o pós-1930, sobre a sindicalização, a previdência social e a Justiça do Trabalho.

Sua função foi subtrair do mercado o litígio entre capital e trabalho, esvaziando-o de seu conteúdo de conflito de interesses e cooptandoo para a mediação da burocracia estatal:

Os direitos elementares do trabalho, encorpado com a legislação do salário mínimo e com os benefícios da previdência social, beneficiando em massa os assalariados, correspondiam à contraprestação "outorgada” pelo Estado à “contenção sindical”. Em razão disso, o ente responsável pela coerção política do proletariado se transfigurava na figura de um benefactor, e não é à toa que o inspirador dessa política chegou a ser conhecido como o pai dos pobres (VIANNA, 1978, p. 241).

Porém, se o Estado Novo é o auge desse projeto de "invenção do trabalhismo" (GOMES, 2005), é preciso observar os esforços empreendidos desde 1930. Nesse período, foram promulgadas quase todas as leis que passaram a regular as relações de trabalho no Brasil, desde as condições de trabalho de menores e mulheres, os contratos de trabalho (jornadas, remuneração, férias), compensações sociais (previdência e assistência social) até a organização das instituições de enfrentamento dos conflitos de trabalho entre patrões e empregados (Comissões e Juntas de Conciliação, Comissões Coletivas de Trabalho). 
Trabalho e educação são dimensões que marcaram fortemente a história daquele período, no qual extensa legislação educacional e trabalhista foi desenvolvida para sustentar as bases do desenvolvimento econômico do país e do projeto político que liderava a construção do Estado. Acontece que os professores, além de agentes educativos, elevados a uma condição importante, dado o significado assumido pela educação para o êxito do projeto político e econômico em curso, foram também envolvidos, enquanto trabalhadores, em processos que repercutiram diretamente sobre sua profissão, posto que o Estado buscou regular o campo de atuação profissional dos professores.

Pela nova regulamentação, o registro profissional no Ministério do Trabalho era condição para o exercício remunerado do ofício nos estabelecimentos particulares de ensino. Para obter o registro profissional, cujo número constaria na carteira profissional, era preciso comprovar inscrição no Registro de Professores do Ministério da Educação. Ou seja, o acesso ao reconhecimento do trabalhador como profissional, mediante registro no Ministério do Trabalho, estava atrelado ao prévio reconhecimento da habilitação do professor pelo Ministério da Educação. Ademais, em estudo posterior sobre a regulamentação da remuneração dos professores, uma comissão do Ministério da Educação situava o decreto de instituição do registro profissional como "providência de grande alcance no sentido da 'qualificação profissional' do professor" (BRASIL, 1940b, p. 15).

O decreto de 1940 sobre o registro profissional, conforme já destacado, contemplava prescrições concernentes às "condições de trabalho dos professores" (BRASIL, 1940a). As principais determinações desse decreto que atenderam a diversos pontos do projeto do Sindicato dos Professores do Distrito Federal foram: o registro profissional dos professores e auxiliares da administração escolar no Ministério do Trabalho; jornada diária de trabalho de até seis horas, com 90 minutos para descanso ou refeição após três aulas consecutivas; proibição de trabalho aos domingos; remuneração por aula com pagamento mensal, considerando o mês com quatro semanas e meia; direito de faltas sem desconto do salário por até nove dias, por motivo de gala, luto ou falecimento de familiares; remuneração por aulas extras; pagamento regular, conforme o horário do período de aulas no período de exames e de férias; limite de oito horas de trabalho no período de exames com o pagamento de horas extras. Os estabelecimentos de ensino deveriam observar a remuneração "condig- 
na", mensal e pontual dos professores, a fim de não ver impedido seu funcionamento regular (COELHO, 1988, p. 117).

Para efeitos de fiscalização a ser realizada pelo Ministério do Trabalho, os colégios deveriam afixar, na secretaria da escola, um quadro de seu corpo docente com os nomes, números de registros e de carteira profissional, assim como manter o Livro de Registro de Professores com as datas de admissão, condições de trabalho, etc.

A respeito da remuneração dos professores, o decreto de 1940 atribuía ao Ministério da Educação e Saúde a competência para estabelecer os critérios sobre a remuneração "condigna" a ser assegurada aos professores do magistério particular, que, como já visto, foi a solução encontrada por Valdemar Falcão para resolver as divergências entre os membros da comissão de trabalho.

A propósito da nova regulamentação, cabe ressaltar que alguns de seus dispositivos já eram praticados pelos estabelecimentos, mas sem obrigatoriedade. Ainda houve resistência de diretores e proprietários de escolas em reconhecer os professores como trabalhadores com direitos à proteção da legislação social emergente.

Em função das fontes disponíveis, é possível acompanhar o processo de elaboração da legislação destinada a regulamentar os contratos de trabalho do magistério, com direitos e deveres estabelecidos. E verificar, assim, a forma como esse processo ocorria em um contexto histórico em que o poder legislativo foi progressivamente apropriado pelo poder executivo, tendência consolidada pela implantação do Estado Novo.

Mas o processo de fortalecimento do Executivo não significou a instauração de um Estado neutro, equidistante dos demais setores sociais. Em função da análise realizada por Eli Diniz, observando a interdependência dos processos sociais e políticos, o Estado Novo, dada a "complexidade e heterogeneidade do aparelho estatal", é aqui entendido como "um conjunto diferenciado e não monolítico de estruturas de decisão" (1997, p. 86). O autoritarismo corporativista do Estado Novo canalizou para o interior da máquina estatal as demandas de diversos setores sociais, efetivando uma acomodação desses setores no poder, colocando-se como árbitro dos conflitos, "em nome dos interesses da nação" (DINIZ, 1997, p. 85).

Portanto, com a instauração do Estado Novo, consolida-se um estado forte e centralizador que corresponde a um novo arranjo de grupos 
sociais. Ao estabelecer novas formas de participação política, por uma "redefinição dos canais de acesso e influência", a interferência dos novos atores sociais, acomodados na burocracia estatal, se faria sentir a partir de então.

Nesse sentido entende-se por que, no período de 1930 a 1945, a formulação de políticas públicas para várias dimensões da organização social, pela montagem de um Estado Nacional, atraiu para as instituições e burocracia estatais intelectuais de diversas áreas do saber. A atuação desses intelectuais informa "sobre campos distintos de concepção da política e de adesão a valores" (BOMENY, 2001, p. 17).

Assim deve-se considerar relativa a autonomia política do Estado, pois a atuação desses grupos poderia impor "certos limites ao campo de ação do executivo, reduzindo ou ampliando a margem de alternativas possíveis ou definindo cursos legítimos de ação" (BOMENY, 2001, p. 17). Por meio de comissões de estudos, relatórios, anteprojetos, substitutivos, pareceres e discursos, os ministros do MES e do MTIC, patrões e empregados encaminharam suas propostas, manifestaram resistências, articularam alianças, interferindo nos rumos do processo decisório.

É sob essa perspectiva que a pesquisa da história da profissão docente nos anos de 1930 e 1940 precisa investigar as iniciativas do Estado no campo educacional e no campo da legislação social e trabalhista, a fim de notar as repercussões na profissionalização da categoria. Mas é necessário também considerar a autonomia relativa do Estado e situar a atuação dos docentes e empregadores nesse processo, o lugar que esses sujeitos ocupam nas relações sociais e do papel que eles jogam na manutenção da ordem social (NÓVOA, 1991, p. 123).

Ademais, a compreensão da criação do registro profissional do magistério de estabelecimentos particulares de ensino deve situar-se em face de dois aspectos principais. O primeiro é o contexto histórico de organização das relações de trabalho no país em novas bases, buscando ingressar o Brasil numa nova fase de seu desenvolvimento econômico, na qual a industrialização assume grande relevância. Os estudos sobre o desenvolvimento do capitalismo no país apontam a primazia do Estado na condução dessas transformações. A "invenção do trabalhismo", naquele momento, foi um ingrediente essencial para a reestruturação das forças produtivas do país.

O segundo aspecto diz respeito à relação da criação do registro profissional com outras políticas públicas que emergem conjuntamente, e 
por vezes atreladas (como é o caso do Registro de Professores no MES e da criação da Faculdade Nacional de Filosofia), que incidem sobre a profissionalização do magistério de Ensino Secundário no país. É um movimento que atinge a reorganização do estatuto da função docente no campo educacional.

Há uma passagem nos estudos da comissão sobre a "remuneração condigna" dos professores que alude a esses dois aspectos. Nesse documento, nota-se que o registro profissional pode ser interpretado tanto como decorrente do princípio constitucional que obrigava o Estado a proteger o trabalho - o que justificava a instauração da comissão interministerial para regulamentar o assunto - quanto "relembra, por seu contexto, [do registro profissional] que para lograr condições favoráveis e meios de defesa, o trabalho deverá revestir-se em cada caso, dos caracteres de uma profissão definida" (BRASIL, 1940b).

O Sindicato dos Professores do Distrito Federal (1940) recebeu com entusiasmo a instituição do registro profissional e organizou homenagem ao ministro do Trabalho, Valdemar Falcão. Também encaminhou ao presidente Getúlio Vargas memorial em que agradecia a sanção do decreto: "primeiro gesto de amparo oficial aos laboriosos educadores da juventude brasileira", de grande significação para o magistério particular do país. Justificavam a confiança e a esperança depositadas no chefe da nação, "primeiro educador do povo brasileiro", para a solução dos problemas do magistério:

[...] habituados a serem escorraçados, incompreendidos em sua sagrada função, ou melhor, repetindo as palavras de V. Excia., no seu "apostolado cívico", posto que a ação de governo do Presidente não esqueceria de premiar os inauditos esforços dos educadores da juventude brasileira (SINDICATO DOS PROFESSORES DO DISTRITO FEDERAL, 1940).

O memorial apresentava citações de discursos do presidente Vargas a fim de articular uma comunhão de ideias entre o "Chefe da Nação" e o pensamento do sindicato sobre a importância do magistério. Mencionava também o trabalho dos chefes das pastas do Trabalho e Educação como "baluartes indefesos das nossas reivindicações, os quais tudo fizeram e tudo farão para permitir condições mais dignas e justas para os professores do Brasill". Segundo o memorial, a significação da nova regulamentação sobre o trabalho do magistério incutiria nos profes- 
sores "um sentimento de respeito e gratidão [que] os impulsionará para a luta mais decidida em prol do aperfeiçoamento da nossa juventude" (SINDICATO DOS PROFESSORES DO DISTRITO FEDERAL, 1940).

Em face da importância da questão salarial para o magistério particular, o sindicato solicitava a conclusão dos estudos da comissão instituída em abril daquele ano para contemplar o tema. Os professores reivindicavam a estabilidade após dois anos no emprego e alegavam que "os professores tornar-se-ão mais eficientes assim que seu trabalho, melhor remunerado, lhes permita dedicar mais tempo ao preparo pessoal. Professor mal pago não pode ter estímulo, e, mais ainda, não poderá aperfeiçoar-se continuamente" (SINDICATO DOS PROFESSORES DO DISTRITO FEDERAL, 1940). Nota-se, aqui, que os argumentos dos professores são inversos ao que prescrevia Lourenço Filho nos trabalhos da comissão sobre a qualificação do magistério. Os professores priorizavam a organização do estatuto econômico da profissão para, então, haver melhor habilitação do magistério, enquanto Lourenço Filho vinculava melhores condições de habilitação como plataforma para melhorar a remuneração do professorado.

A relação entre habilitação, enquanto qualificação profissional do magistério e formação específica para o ofício a ser exercido, e a remuneração, entendida como essencial para o reconhecimento de uma atividade como profissionalizada e exercida por um grupo específico, permite notar as imbricações nas políticas de profissionalização do magistério. Até mesmo porque, no caso da qualificação e da remuneração, foi instituída uma mesma comissão, mas que acabou por separar a normatização dos dois assuntos em pauta, devido a divergências no interior da comissão, o que postergou a definição dos critérios da remuneração.

Dado que o Estado Novo não correspondeu a um conjunto monolítico, havendo colaboração, mas também divergências entre os órgãos estatais, o Sindicato dos Professores encaminhou suas propostas e solicitações ao Ministério do Trabalho e ao Ministério da Educação. Nos conflitos no interior da burocracia estatal, na qual professores e empregadores, por meio de seus canais de acesso e influência, buscavam influir nos rumos das políticas que lhes interessavam, foi vitoriosa a tendência que buscou reconhecer o professor como trabalhador do ensino, fracassando a intenção dos empregadores de manter seus estabelecimentos à margem das leis trabalhistas, da fiscalização e da Justiça do Trabalho. 
Contudo, cabe notar que o reconhecimento, por meio de legislação, da condição do magistério como profissão, com contratos de trabalho regulados por lei, não significou a garantia do cumprimento da legislação por parte dos empregadores.

\section{Conclusão}

Nos estudos da implantação do Registro Profissional no Ministério do Trabalho e na regulamentação dos contratos de trabalho residem aspectos importantes do processo de profissionalização do magistério particular de Ensino Secundário no Brasil. Nota-se, ainda, que questões relativas à profissionalização docente, naquele contexto, devem ser pensadas à luz de um movimento mais amplo, que ocorria e era pertinente não apenas aos trabalhadores do ensino, mas ao conjunto das relações sociais de trabalho. Tratava-se do processo histórico de implantação do capitalismo industrial no país, com forte atuação da sociedade política na condução do processo de edificação de um novo formato de Estado.

Quanto à abordagem acadêmica sobre as relações entre Estado e classe trabalhadora naquele cenário, nota-se, na confrontação do balanço historiográfico sobre o tema (MATTOS, 2002) com as fontes de pesquisa, que, ainda que organizados sob o regime sindical tutelado e sob lideranças compromissadas com o governo, os Sindicatos de Professores souberam usar os canais de acesso e influência e as formas de jogo político instituídos no pós-1930. Por meio dessas brechas, fizeram suas reivindicações e marcaram posições na correlação de forças que consubstanciaram as disputas sobre os rumos da profissionalização docente, ainda que não tenham conseguido a hegemonia desse processo, em face das relações cartoriais do governo com os empregadores, bem como da força política significativamente maior dos empregadores na configuração do Estado.

Dessa forma, mesmo que a legislação social e trabalhista tenha sido concebida para permanecer "letra morta" e que não tenha correspondido exatamente a uma conquista da classe trabalhadora, ela se tornou um referencial para lutar por direitos sonegados (FRENCH, 1995). Sob essa ótica, percebe-se que a organização sindical do magistério se organizou para regulamentar e, portanto, dar vias de execução a dispositivos presentes na lei que talvez se mantivessem "letra morta", se não fosse a mobi- 
lização dos professores. Eles recorreram a negociações com o empresariado pela mediação de setores da burocracia estatal, ou seja, o MES e o MTIC, e também souberam apelar ao executivo quando suas demandas pareciam estagnar diante de divergências entre essas instâncias. Nesse sentido, deslocamos o eixo de observação da profissionalização docente como resultado da ação estatal, num sentido restrito, pois, afinal, a participação de atores coletivos organizados na sociedade civil caracterizou também o processo de profissionalização.

Foi por meio do intervencionismo estatal nas relações entre os empregadores e os "trabalhadores do ensino" que os dispositivos da legislação trabalhista e social foram estendidos aos docentes. A atuação dos professores nesse processo, pela via sindical, foi importante para a inserção do magistério no referencial normativo das relações de trabalho, o que também concorreu, juntamente com outras iniciativas estatais, para a transformação do estatuto profissional do magistério. 


\section{Referências}

BOMENY, Helena. Infidelidades Eletivas: Intelectuais e Políticas. In: BOMENY, Helena. (Org.). Constelação Capanema: intelectuais e políticas. Rio de Janeiro: FGV, 2001, p. 10-35.

BRASIL. Decreto n. 19.890, de 18 de abril de 1931. Dispõe sobre a organização do Ensino Secundário. Coletânea de Legislação Federal. Disponível em:

<www.senado.gov.br/sicon>. Acesso em: 10 out. 2007.

BRASIL. Decreto-lei n. 21.241, de 4 de abril de 1932. Última Lei do Ensino Secundário. Novos Programas organizados pelo Departamento Nacional do Ensino para admissão à $1^{\mathrm{a}}$ série do curso secundário. Consolida as disposições sobre a organização do ensino secundário e dá outras providências. Disponível em: <www.senado.gov.br/sicon>. Acesso em: 08 out. 2007.

BRASIL. Decreto-lei n. 2.028, de 22 de fevereiro de 1940a. Institui o Registro Profissional dos Professores e Auxiliares da Administração Escolar, Dispõe sobre as condições de trabalho dos empregados em estabelecimentos particulares de ensino e dá outras providências. Disponível em: <www.senado.gov.br/sicon>. Acesso em: 10 jul. 2007.

BRASIL. Consolidação das Leis do Trabalho. Seção XII. Dos Professores. Decreto-lei n. 5.452 de 01/05/1943. In: NÓBREGA, Vandick Londres. Enciclopédia da Legislação do Ensino. v. 1. Rio de Janeiro, [s.n.], p. 487-488.

BRASIL. Ministério da educação e saúde. Relatório Geral da Comissão Especial para fixação dos critérios a serem adotados na determinação da remuneração condigna dos professores em estabelecimentos particulares do ensino, apresentado ao Ministro da Educaşão Gustavo Capanema, p. 15, 30/08/1940b. FGV, CPDOC. GC g 1937.07.13, r. 48, Pasta I, p. 11.

CAPANEMA, Gustavo. Emendas apresentadas por Gustavo Capanema ao Presidente Vargas ao projeto apresentado pelo Ministério do Trabalho sobre o registro profissional dos professores e auxiliares da administração escolar. 12/02/1940. FGV, CPDOC. GC g 1937.07.13, pasta I, r 48.

COELHO, Ricardo B. Marques. O sindicato dos professores e os estabelecimentos particulares de ensino no Rio de Janeiro 1931 - 1950. 1988. 215 f. Dissertação (Mestrado em História) Instituto de Ciências Humanas e Filosofia, Universidade Federal Fluminense, Niterói, 1988.

DIAS, Amália. Apostolado cívico e trabalhadores do ensino: história do magistério do ensino secundário no Brasil (1931-1946). 2008. 254f. Dissertação (Mestrado em Educação) Faculdade de Educação, Universidade Federal Fluminense, Niterói, 2008.

DINIZ, Eli. O Estado Novo: Estruturas de Poder. Relações de Classe. In: FAUSTO, Boris (Org.). História Geral da Civilização Brasileira. Rio de Janeiro: Bertrand Brasil, 1997. t. 3 , v. 3 .

FALCÃO, Waldemar. Exposição de Motivos do Ministério do Trabalho ao Presidente Getúlio Vargas referente a anteprojeto sobre registro profissional do magistério de estabelecimentos particulares de ensino, 24/10/1939: FGV, CPDOC. GC g 1937.07.13, pasta I, r. 48.

FRENCH, John D. $O A B C$ dos operários. Conflitos e alianças de classe em São Paulo, 1900-1950. São Paulo: Hucitec/Pref. Mun. De São Caetano do Sul, 1995.

GOMES, Ângela de Castro. A invenção do trabalhismo. 3 ed. Rio de Janeiro: FGV, 2005. GRAMSCI, Antonio. Cadernos do Cárcere. Maquiavel. Notas sobre o Estado e a Política. 
Rio de Janeiro: Civilização Brasileira, 2007. v. 3.

LOURENÇO FILHO, M. Contribuição referente a "qualificação" do professor, 17/03/1939: FGV, CPDOC. GC g 1937.07.13, r. 48.

LOURENÇO FILHO, M. Carta a Gustavo Capanema, 29/09/1940: FGV, CPDOC. GC g 1937.07.13, pasta I, r. 48.

MATTOS, Marcelo Badaró. Os desafios da História do trabalho hoje - pensando a partir da produção do Rio de Janeiro. Jornadas de História do Trabalho. Participação no painel Os desafios da História do trabalho hoje. 2002. Disponível em:

http://www.labhstc.ufsc.br/VI\%20jornada\%20trabalho/mesa\%20pelotas.doc. Acesso em: 31 jan. 2008.

NÓVOA, António. Para o estudo sócio-histórico da gênese e desenvolvimento da profissão docente. Teoria e Educação, Porto Alegre, n. 4, p. 109-139, 1991.

ROCHA, Marlos Bessa Mendes da. Educação Conformada: a política pública de educação no Brasil:1930-1945. Juiz de Fora: Ed. UFJF; Brasília: Mec/Inep/Comped, 2000.

SINDICATO DOS PROFESSORES DO DISTRITO FEDERAL. Memorial do Sindicato de Professores ao Presidente da República, s/d.: FGV, CPDOC. GC g 1937.07.13, pasta II, r. 48.

VIANNA, Luiz Werneck. Liberalismo e Sindicato no Brasil. Rio de Janeiro: Paz e Terra, 1978.

VICENTINI, Paula Perin; LUGLI, Rosario S. Genta. O Magistério Secundário como Profissão: o associativismo docente e a expansão do sistema educacional brasileiro entre os anos 1940 e 1960. Revista da FAEEBA - Educação e Contemporaneidade, Salvador, v. 14, n. 24 , p. $57-73$, jul.-dez. 2005.

\section{Notas}

1 Pela Lei n. 378, de 13 de janeiro de 1937, o Ministério da Educação e Saúde Pública passou a denominar-se Ministério da Educação e Saúde. Disponível em: www.senado.gov.br/sicon. Acesso em 10 jan. 2007. 